\title{
Desempenho agronômico da cultivar de amendoim Granoleico em diferentes épocas de semeadura em Sorriso- MT
}

\author{
Submetido - 27 jul. $2020 \quad$ Aprovado - 20 set. $2020 \quad$ Publicado - 14 out. 2020
}

http://dx.doi.org/10.17648/sas.v1i2.40

\begin{abstract}
Professora do Instituto Federal de Educação, Ciência e Tecnologia de Mato Grosso - IFMT, Sorriso, MT, e-mail: ana.olibone@srs.ifmt.edu.br.
\end{abstract}

Ana Paula Encide Olibone (iD)

Dácio Olibone (i)

Professor do Instituto Federal de Educação, Ciência e Tecnologia de Mato Grosso - IFMT, Sorriso, MT, e-mail: dacio.olibone@srs.ifmt.edu.br.

Jair Heuert ${ }^{\text {iD }}$

Programa de Melhoramento do Amendoim - Embrapa, Santo Antônio de Goiás, GO, e-mail: jair.heuert@embrapa.br.

João Lucas Lopes Silva iD

Discente de Engenharia Agronômica, Instituto Federal de Educação, Ciência e Tecnologia de Mato Grosso - IFMT, Sorriso, MT, e-mail: jllopes244@gmail.com.

Maxuel Fellipe Nunes Xavier (iD Discente de Agronomia, Instituto Federal de Educação, Ciência e Tecnologia de Mato Grosso - IFMT, São Vicente - Centro de Referência de Campo Verde, Campo Verde, MT, e-mail: maxuelfellipe90@gmail.com.

Timóteo da Gama ${ }^{\mathbb{D}}$

Discente de Engenharia Agronômica, Instituto Federal de Educação, Ciência e Tecnologia de Mato Grosso - IFMT, Sorriso, MT, e-mail: timotio.theo@gmail.com.

\section{RESUMO}

O objetivo deste estudo é determinar a melhor época de semeadura para cultivar de amendoim Granoleico nas condições de Sorriso-MT. O experimento foi realizado na área experimental do Instituto Federal de Educação, Ciência e Tecnologia - IFMT Campus Sorriso, localizado no município de Sorriso-MT. Foi utilizado o delineamento em blocos casualizados, com 3 repetições. Os tratamentos foram 6 épocas de semeadura $\left(1^{a}-07 / 11 / 2019,2^{a}-28 / 11 / 2019\right.$, $3^{a}$ 19/12/2019, 4 - 09/01/2020, 5 - 30/01/2020 e 6 - 13/02/2020). A cultivar de amendoim foi a Granoleico, desenvolvida pelo Criadero El Carmen da Argentina. As parcelas foram compostas por 4 linhas de 4 metros de comprimento e espaçamento de 0,90 m. As duas linhas centrais foram consideras como área útil, totalizando $7,2 \mathrm{~m}^{2}$ por parcela. Por ocasião da maturação das vagens, foram colhidas as plantas da área útil aos 140 dias após a emergência (DAE) para 1ạ, $2^{a}, 3^{a}$ e $4^{a}$ épocas de semeadura, aos 117 DAE para 5á época e ao 109 DAE a 6ª época de semeadura, pois as vagens estavam no devido ponto de maturação nas respectivas épocas. Foi determinado a produtividade de vagens ( $\left.\mathrm{kg} \mathrm{ha}^{-1}\right)$, rendimento de grãos (\%), massa de 100 grãos (g), número de vagens por planta, número de grãos por planta e número de grãos por vagem. As variáveis número de vagens por planta, número de grãos por planta e massa de 100 grãos não obtiveram diferença significativa em função das épocas de semeadura da cultivar Granoleico. Somente a época 07 de novembro obteve o menor resultado de número de grãos por vagem em relação as demais épocas. Os melhores rendimentos foram obtidos nas épocas 09 de janeiro e 19 de dezembro. A época 07 de novembro resultou na maior produtividade de vagens. Por fim, constata-se a necessidade de outros estudos para obtenção da confirmação dos resultados obtidos nas condições de Sorriso-MT.

Palavras-chave: Arachis hypogaea L.; Produtividade; Amendoim no Mato Grosso. 


\title{
Agronomic performance of Granoleico peanuts under different sowing times of Sorriso-MT
}

\begin{abstract}
The objective of this study is to determine the best sowing time to cultivate Granoleico peanuts under the conditions of Sorriso-MT. The experiment was carried out in the experimental area of the Federal Institute of Education, Science and Technology - IFMT Campus Sorriso, located in the city of Sorriso-MT. A randomized block design with 3 replications was used. The treatments were 6 sowing times (1st - 11/07/2019, 2nd - 11/28/2019, 3rd - 12/19/2019, 4th - 01/09/2020, 5th 01/30/2020 and 6th - 02/13/2020). The peanut cultivar was Granoleico, developed by Criadero EI Carmen from Argentina. The plots were composed of 4 lines of 4 meters in length and spacing of $0.90 \mathrm{~m}$. The two central lines were considered as a useful area, totaling $7.2 \mathrm{~m}^{2}$ per plot. When pods matured, plants from the useful area were harvested 140 days after emergence (DAE) for the 1st, 2nd, 3rd and 4th sowing seasons, at 117 DAE for 5th season and at 109 DAE the 6th sowing season, because the pods were at the proper point of maturation in the respective seasons. Pod yield (kg ha $\left.{ }^{-1}\right)$, grain yield (\%), mass of 100 grains (g), number of pods per plant, number of grains per plant and number of grains per pod were determined. The variables number of pods per plant, number of grains per plant and mass of 100 grains did not obtain a significant difference due to the sowing times of the cultivar Granoleico. Only the november 7 season obtained the lowest number of grains per pod in relation to the other seasons. The best yields were obtained on the 9th of january and the 19th of december. The november 7 season resulted in the highest pod productivity. Finally, there is a need for further studies to obtain confirmation of the results obtained under the conditions of Sorriso-MT.
\end{abstract}

Keywords: Arachis hypogaea L.; Productivity; Peanuts in Mato Grosso.

\section{Rendimiento agronómico de maní Granoleico en diferentes tiempos de siembra bajo de Sorriso-MT}

\section{RESUMEN}

El objetivo de este estudio es determinar el mejor momento de siembra para cultivar maní Granoleico en las condiciones de Sorriso-MT. El experimento se llevó a cabo en el área experimental del Instituto Federal de Educación, Ciencia y Tecnología - IFMT Campus Sorriso, ubicado en la ciudad de Sorriso-MT. Se utilizó un diseño de bloques al azar con 3 repeticiones. Los tratamientos fueron 6 tiempos de siembra (1 $1^{a}$ - 07/11/2019, $2^{a}-28 / 11 / 2019,3^{a}-19 / 12 / 2019,4^{a}$ - 09/01/2020, 5a - 30/01/2020 y 6 - 13/02/2020). El cultivar de maní fue Granoleico, desarrollado por Criadero El Carmen de Argentina. Las parcelas estaban compuestas por 4 líneas de 4 metros de longitud y un espaciado de $0.90 \mathrm{~m}$. Las dos líneas centrales se consideraron superficie útil, totalizando $7,2 \mathrm{~m}^{2}$ por parcela. Cuando las mazorcas maduraron, las plantas del área útil se cosecharon 140 días después de la emergencia (DAE) para la 1ạ, 2a, $3^{a}$ y $4^{a}$ temporada de siembra, a 117 DAE para la 5ª temporada y a 109 DAE la 6 $6^{a}$ temporada, porque las vainas se encontraban en el punto adecuado de maduración en las temporadas respectivas. Se determinó rendimiento de vaina $\left(\mathrm{kg} \mathrm{ha}^{-1}\right)$, rendimiento de grano (\%), masa de 100 granos (g), número de vainas por planta, número de granos por planta y número de granos por vaina. Las variables número de vainas por planta, número de granos por planta y masa de 100 granos no obtuvieron una diferencia significativa debido a los tiempos de siembra del cultivar Granoleico. Solo la temporada 7 de noviembre obtuvo el menor número de granos por vaina en relación a las otras temporadas. Los mejores rendimientos se obtuvieron el 9 de enero y el 19 de diciembre. La temporada del 7 de noviembre resultó en la mayor productividad de vainas. Finalmente, es necesario realizar más estudios para obtener la confirmación de los resultados obtenidos en las condiciones de Sorriso-MT.

Palabras clave: Arachis hypogaea L.; Productividad; Maní en Mato Grosso. 


\section{Introdução}

As culturas anuais e leguminosas, ganham espaço durante a época de renovação de canaviais. Está prática ocorre a cada cinco anos, quando a cana-de-açúcar precisa ser replantada, e neste intervalo de semeaduras, muitos agricultores ou usinas cedem a área para o cultivo de culturas anuais (CHIES, 2018).

A cultura do amendoim (Arachis hypogaea L.) é utilizada por muitos agricultores para fazer rotação com a cana-de-açúcar nas áreas de reforma no estado de São Paulo. Porém, ultimamente, há um crescimento na escolha do cultivo da soja neste sistema de rotação, pois esta cultura vem ganhando força no estado e disputando de modo acirrado com o amendoim na preferência dos canavicultores e das usinas (BOLONHEZI, 2020).

Dessa forma, a região Centro Oeste, especialmente o médio norte de Mato Grosso, apresenta reconhecida aptidão agrícola, terras favoráveis ao cultivo e a mecanização em larga escala, clima bem definido, produtores ávidos por alternativas econômicas voltadas ao mercado externo, o que pode contribuir para a expansão do cultivo de amendoim no Brasil (LAZAROTTO, 2020). Nesse sentido, o objetivo deste estudo é determinar a melhor época de semeadura para cultivar de amendoim Granoleico nas condições de Sorriso-MT.

\section{Material e métodos}

O experimento foi realizado em campo, na área experimental do Instituto Federal de Educação, Ciência e Tecnologia - IFMT Campus Sorriso, localizada à latitude $12^{\circ} 41^{\prime} 43^{\prime \prime} \mathrm{S}$, longitude $55^{\circ} 48^{\prime} 07^{\prime \prime} \mathrm{W}$ e altitude média de $358 \mathrm{~m}$, em solo classificado como Latossolo Vermelho Amarelo distrófico com textura argilosa. O clima da região é tipo Aw, com temperatura média de $26,2^{\circ} \mathrm{C}$ e pluviosidade média de $1970 \mathrm{~mm}$ anuais os quais são distribuídos nos meses de outubro a abril (SOUZA et al., 2013).

Foi utilizado o delineamento em blocos casualizados, com 3 repetições. Os tratamentos foram 6 épocas de semeadura (1르- 07/11/2019, 
$2^{a}-28 / 11 / 2019,3^{a}-19 / 12 / 2019,4^{a}-09 / 01 / 2020,5^{a}-30 / 01 / 2020$ e $6^{a}-$ 13/02/2020). A cultivar de amendoim foi a Granoleico, desenvolvida pelo Criadero El Carmen da Argentina. As parcelas foram compostas por 4 linhas de 4 metros de comprimento e espaçamento de $0,90 \mathrm{~m}$. As duas linhas centrais foram consideras como área útil, totalizando $7,2 \mathrm{~m}^{2}$ por parcela.

Anterior a implantação do experimento, foi efetuado o levantamento da fertilidade e granulometria do solo, utilizando-se metodologia proposta por Raij et al. (2001) e Embrapa (1997), na profundidade de 0 a 0,20 m. Os resultados das análises foram: $\mathrm{pH}\left(\mathrm{CaCl}_{2}\right)$ 5,30; $\mathrm{P}$ (resina) $5,0 \mathrm{mg} / \mathrm{dm}^{3} ; \mathrm{K} 78$

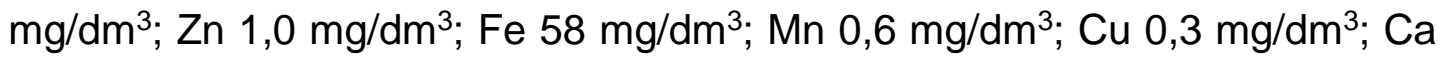
19 mmolc/dm ${ }^{3}$; Mg 14 mmolc/dm ${ }^{3}$; Al 1 mmolc/ $/ \mathrm{dm}^{3}$ e $\mathrm{H}+\mathrm{Al} 40 \mathrm{mmolc} / \mathrm{dm}^{3}$ com saturação por bases $46 \%$ e matéria orgânica 2,0\%. A análise granulométrica de areia, silte e argila apresentou 434, 26 e $540 \mathrm{~g} \mathrm{dm}^{-3}$, respectivamente. Visando aumentar a saturação por bases para $60 \%$, foi realizado calagem de 1,4 ton ha-1 de calcário dolomítico, 60 dias antes da semeadura da primeira época, sendo este incorporado com 2 gradagens.

Em todas as épocas, as sementes foram tratadas com carboxina + tiram e distribuídas na densidade de 28 sementes por metro (germinação 90\%). A adubação de base consistiu na aplicação de $300 \mathrm{~kg} \mathrm{ha}^{-1}$ do formulado NPK 04-30-10, distribuído no sulco de semeadura. Em cobertura, aos 35 dias após a emergência (DAE), foi realizada a aplicação de $500 \mathrm{~kg}$ $\mathrm{ha}^{-1}$ de gesso agrícola, aplicado a lanço em área total. $\mathrm{O}$ manejo fitossanitário foi feito conforme a recomendação para a cultura do amendoim.

Por ocasião da maturação das vagens, foram colhidas as plantas da área útil aos 140 dias após a emergência para $1^{\underline{a}}, 2^{\underline{a}}$, $3^{\underline{a}}$ e $4^{\underline{a}}$ épocas de semeadura, aos 117 DAE para 5 época e ao 109 DAE a 6ª época de semeadura, pois as vagens estavam no devido ponto de maturação nas respectivas épocas. Foi determinado a produtividade de vagens ( $\mathrm{kg} \mathrm{ha}^{-1}$ ) (corrigindo a umidade dos grãos a 8\%), rendimento de grãos (\%), massa de 100 grãos (g), número de vagens por planta, número de grãos por planta e número de grãos por vagem. 
Os dados foram submetidos à análise de variância pelo teste $\mathrm{F}$ e as médias dos tratamentos foram agrupados pelo teste de Scott-Knott a 5\% de probabilidade utilizando o programa estatístico SISVAR (FERREIRA, 2019).

\section{Resultados e discussão}

As épocas de semeadura de amendoim cultivar Granoleico não apresentaram diferença significativa para as variáveis número de vagens por planta e número de grãos por planta. Somente a variável número de grãos por vagem apresentou diferença significativa em função das diferentes épocas de semeadura da cultivar (Tabela 1).

Tabela 1. Número de vagens por planta (NVP), número de grãos por planta (NGP) e número de grãos por vagem (NGV) de amendoim cultivar Granoleico em função diferentes épocas de semeadura. Sorriso-MT, 2019/20.

\begin{tabular}{|c|c|c|c|}
\hline \multirow{2}{*}{$\begin{array}{l}\text { Épocas de } \\
\text { Semeadura }\end{array}$} & NVP & NGP & NGV \\
\hline & \multicolumn{3}{|c|}{ - } \\
\hline 1a -07 de novembro & $17,5 \mathrm{a}$ & $23,7 \mathrm{a}$ & $1,4 \mathrm{~b}$ \\
\hline $2^{\mathrm{a}}-28$ de novembro & $15,5 \mathrm{a}$ & $27,3 \mathrm{a}$ & $1,8 \mathrm{a}$ \\
\hline $3^{a}-19$ de dezembro & $20,4 \mathrm{a}$ & $35,9 \mathrm{a}$ & $1,7 \mathrm{a}$ \\
\hline $4^{\mathrm{a}}-09$ de janeiro & $18,6 \mathrm{a}$ & $30,0 \mathrm{a}$ & $1,6 \mathrm{a}$ \\
\hline $5^{\mathrm{a}}-30$ de janeiro & $18,3 \mathrm{a}$ & $30,4 \mathrm{a}$ & $1,7 \mathrm{a}$ \\
\hline $6^{\mathrm{a}}-13$ de fevereiro & $12,9 \mathrm{a}$ & $22,2 \mathrm{a}$ & $1,7 \mathrm{a}$ \\
\hline $\mathrm{F}$ & $0,6863^{\text {ns }}$ & $0,5736^{\mathrm{ns}}$ & $0,0001^{*}$ \\
\hline C.V. (\%) & 33,8 & 34,1 & 3,8 \\
\hline
\end{tabular}

As variáveis número de vagens por planta e número de grãos por planta, mesmo sem diferirem entre si em função das épocas de semeadura, observa-se resultados superiores numericamente nas épocas 19 de dezembro (20,4 vagens por planta e 35,9 grãos por planta), 09 de janeiro (18,6 vagens por planta e 30,0 grãos por planta) e 30 de janeiro (18,3 vagens por planta e 30,4 grãos por planta).

Quanto ao número de grãos por vagem, observa-se que a época de semeadura 07 de novembro obteve 0 menor resultando (1,4 grãos por 
vagem) quando comparado as demais épocas (28 de novembro, 19 de dezembro, 09 de janeiro, 30 de janeiro e 13 de fevereiro) que obtiveram de 1,6 a 1,8 grãos por vagem.

As épocas de semeadura de amendoim cultivar Granoleico não apresentaram diferença significativa para a variável massa de 100 grãos (g). Somente as variáveis produtividade de vagens $\left(\mathrm{kg} \mathrm{ha}^{-1}\right)$ e rendimento (\%) apresentaram diferença significativa em função das diferentes épocas de semeadura da cultivar Granoleico (Tabela 2).

Tabela 2. Massa de 100 grãos (g) (M100), produtividade de vagens (kg ha-1) (PROD) e rendimento (\%) (REND) de amendoim cultivar Granoleico em função diferentes épocas de semeadura. Sorriso-MT, 2019/20.

\begin{tabular}{cccc}
\hline Épocas de & M100 & PROD & REND \\
\cline { 2 - 4 } Semeadura & $(\mathrm{g})$ & $\left(\mathrm{kg} \mathrm{ha}^{-1}\right)$ & $(\%)$ \\
\hline 1 $^{\mathrm{a}}-07$ de novembro & $69,4 \mathrm{a}$ & $5.454,6 \mathrm{a}$ & $78,9 \mathrm{~b}$ \\
$2^{\mathrm{a}}-28$ de novembro & $59,3 \mathrm{a}$ & $3.483,5 \mathrm{c}$ & $77,6 \mathrm{~b}$ \\
$3^{\mathrm{a}}-19$ de dezembro & $64,3 \mathrm{a}$ & $4.778,8 \mathrm{~b}$ & $80,6 \mathrm{a}$ \\
$4^{\mathrm{a}}-09$ de janeiro & $62,1 \mathrm{a}$ & $4.384,2 \mathrm{~b}$ & $80,9 \mathrm{a}$ \\
$5^{\mathrm{a}}-30$ de janeiro & $61,2 \mathrm{a}$ & $4.728,1 \mathrm{~b}$ & $79,1 \mathrm{~b}$ \\
$6^{\mathrm{a}}-13$ de fevereiro & $66,1 \mathrm{a}$ & $2.999,8 \mathrm{c}$ & $78,9 \mathrm{~b}$ \\
\hline F & $0,5877^{\mathrm{ns}}$ & $0,0001^{*}$ & $0,0184^{*}$ \\
\hline C.V. $(\%)$ & 11,3 & 8,1 & 1,2 \\
\hline
\end{tabular}

* - significativo a 5\% de probabilidade; ns - não significativo; C.V. coeficiente de variação.

O cultivo na época 07 de novembro resultou na maior produtividade de vagens $\left(5.454,6 \mathrm{~kg} \mathrm{ha}^{-1}\right)$ quando comparada as demais épocas. Observase produtividades intermediárias nas épocas 19 de dezembro $\left(4.778,8 \mathrm{~kg} \mathrm{ha}^{-}\right.$ $\left.{ }^{1}\right), 30$ de janeiro $\left(4.728,1 \mathrm{~kg} \mathrm{ha}^{-1}\right)$ e 09 de janeiro $\left(4.384,2 \mathrm{~kg} \mathrm{ha}^{-1}\right)$. No entanto, as menores produtividades foram obtidas nas épocas 28 de novembro $\left(3.483,5 \mathrm{~kg} \mathrm{ha}^{-1}\right)$ e 13 de fevereiro $\left(2.999,8 \mathrm{~kg} \mathrm{ha}^{-1}\right)$. Constata-se que a época de semeadura 07 de novembro, que apresentou significativamente o menor número de grãos por vagem (1,4 grãos por vagem), obteve a maior produtividade de vagens $\left(5.454,6 \mathrm{~kg} \mathrm{ha}^{-1}\right)$.

Corroborando com o presente estudo, Ribeiro et al. (2018), estudando o desempenho de genótipos de amendoim, obteve com a cultivar 
Granoleico, produtividade de vagens de $4.519,4 \mathrm{~kg} \mathrm{ha}^{-1} \mathrm{com}$ a semeadura realizada 05 de dezembro na Alta Paulista. Nesta mesma vertente de estudos, Ribeiro et al. (2017) obteve produtividade de $3.312 \mathrm{~kg} \mathrm{ha}^{-1} \mathrm{com}$ a cultivar Granoleico semeada no dia 09 de dezembro, em Herculândia-SP. Por outro lado, Martins et al. (2019) obteve produtividade de $6.322,1 \mathrm{~kg} \mathrm{ha}^{-1}$ com a mesma cultivar semeada 08 de dezembro, em Santo Antônio de Goiás-GO.

As épocas de semeadura 28 de novembro $\left(3.483,5 \mathrm{~kg} \mathrm{ha}^{-1}\right)$ e 13 de fevereiro $\left(2.999,8 \mathrm{~kg} \mathrm{ha}^{-1}\right)$, além de apresentarem as menores produtividades de vagens do presente estudo, obtiveram produtividades inferiores 2 e 18\%, respectivamente, a estimativa média nacional de amendoim $1^{\text {a }}$ safra $\left(3.554,0 \mathrm{~kg} \mathrm{ha}^{-1}\right)$ da Companhia Nacional de Abastecimento (2020).

$\mathrm{Na}$ época de semeadura 28 de novembro foi observado visualmente a maior incidência de doenças, em especial as causadas pelos fungos Cercosporidium personatum e Sclerotium rolfsii, favorecido pela alta umidade, podendo ter contribuído para o resultado de menor produtividade de vagens desta época, nas condições experimentais.

A época 13 de fevereiro sofreu interferência climática, no terço final do ciclo do amendoim ocorreu a falta de chuva, algo normal para região, totalizando precipitação de $439 \mathrm{~mm}$ nesta época. Com isso, houve falta de água para frutificação e enchimento de grãos deste período, que também contribuiu para reduzir o ciclo para 109 DAE. A redução da produtividade também foi influenciada pelo solo seco, que dificultou 0 arranquio das plantas e gerou perdas significativas de vagens no solo.

A última época (13 de fevereiro) mesmo sem diferir significativamente na massa de 100 grãos, obteve segunda maior massa, numericamente, podendo-se observar que as vagens produzidas dos primeiros ginóforos emitidos, obtiveram um satisfatório enchimento, porém devido a época ser tardia, as plantas concentraram sua energia no desenvolvimento destas vagens. Possivelmente, a planta não possuía 
reserva energética e hídrica, para desenvolver as vagens formadas posteriormente.

$\mathrm{Na}$ variável rendimento (\%), as maiores porcentagens foram obtidas nas épocas 09 de janeiro $(80,9 \%)$ e 19 de dezembro $(80,6 \%)$. As épocas 30 de janeiro (79,1\%), 13 de fevereiro (78,9\%), 07 de novembro $(78,9 \%)$ e 28 de novembro $(77,6 \%)$ não obtiveram diferença entre si, sendo as menores porcentagens do presente estudo. Uitdewilligen et al. 2017 avaliando o desempenho de genótipos de amendoim, obteve com a cultivar Granoleico, rendimentos de 78 e $79 \%$, nas colheitas realizadas aos 125 e 130 DAE, respectivamente, com semeaduras realizadas 06 de outubro, em Jaboticabal-SP.

\section{Conclusões}

As variáveis número de vagens por planta, número de grãos por planta e massa de 100 grãos não obtiveram diferença significativa em função das épocas de semeadura da cultivar Granoleico. Somente a época 07 de novembro obteve o menor resultado de número de grãos por vagem em relação as demais épocas. Os melhores rendimentos foram obtidos nas épocas 09 de janeiro e 19 de dezembro. A época 07 de novembro resultou na maior produtividade de vagens. Por fim, constata-se a necessidade de outros estudos para obtenção da confirmação dos resultados obtidos nas condições de Sorriso-MT.

\section{Agradecimentos}

Os autores agradecem aos demais discentes do curso de Engenharia Agronômica que contribuíram na condução do experimento. A parceria institucional com o Programa de Melhoramento do Amendoim Embrapa, LC Sementes, MIAC - Indústrias Colombo e a Beatrice Peanuts. 


\section{Referências}

BOLONHEZI, D. Cada vez mais a soja ocupa as áreas de renovação de canaviais. 2020 Disponível em: $<$ http://www.canaonline.com.br/conteudo/cada-vez-mais-a-soja-ocupa-asareas-de-renovacao-de-canaviais.html>. Acesso em: 26 jul. 2020.

Companhia Nacional de Abastecimento. Acompanhamento da safra brasileira de grãos. Monitoramento agrícola, v. 7 - safra 2019/20 - Décimo levantamento, p. 1-74, jul. 2020. Disponível em: <https://www.conab.gov.br/info-agro/safras/graos>. Acesso em: 26 jul. 2020.

CHIES, V. Estudo revela novo perfil da agricultura no nordeste paulista. 2018. Disponível em: <https://www.embrapa.br/en/busca-de-noticias//noticia/38066698/estudo-revela-novo-perfil-da-agricultura-no-nordestepaulista>. Acesso em: 26 jul. 2020.

EMBRAPA. Centro Nacional de Pesquisa de Solos (Rio de Janeiro, RJ). Manual de métodos de análise de solo. 2.ed. Rio de Janeiro EmbrapaCNPS, 1997. 212p.

FERREIRA, D. F. SISVAR: um sistema de análise de computador para efeitos fixos projetos de tipo de partida dividida. Revista Brasileira de Biometria, v. 37, n. 4, p. 529-535, 2019.

LAZAROTTO, C. Referência no cultivo e beneficiamento do amendoim, empresários paulistas estão de olho em Sorriso. 2020. Disponível em: $<$ https://site.sorriso.mt.gov.br/noticia/referencia-no-cultivo-e-beneficiamentodo-amendoim-empresarios-paulistas-estao-de-olho-em-sorriso5e6248ł3d321d>. Acesso em: 25 jul. 2020.

MARTINS, K. B. B.; RODRIGUES, L. L.; HEUERT, J.; XAVIER, M. F. N.; SUASSUNA, T. M. F.; BETIOL, R. A. B. Desempenho agronômico de novas linhagens de amendoim no Cerrado. In: Anais do encontro sobre a cultura do amendoim, 16., 2019, Jaboticabal. Anais eletrônicos... Campinas, GALOÁ, 2019. Disponível em: <https://proceedings.science/encontro-amendoim2019/papers/desempenho-agronomico-de-novas-linhagens-de-amendoimno-cerrado>. Acesso em: 26 jul. 2020.

RAIJ, B.; ANDRADE, J. C.; CANTARELLA, H.; QUAGGIO, J. A. Análise química para avaliação da fertilidade de solos tropicais. Campinas Instituto Agronômico, 2001. 285p.

RIBEIRO, R. P.; SUASSUNA, T. M. F.; HEUERT, J.; SOAVE, J. H.; SANTOS, L. C. C. Desempenho de genótipos de amendoim na Alta Paulista. In: Anais do encontro sobre a cultura do amendoim, 15., 2018, Jaboticabal. Anais eletrônicos... Campinas, GALOÁ, 2018. Disponível em: $<$ https://proceedings.science/encontro-amendoim-2018/papers/desempenhode-genotipos-de-amendoim-na-alta-paulista>. Acesso em: 26 jul. 2020. 
RIBEIRO, R. P.; HEUERT, J.; SUASSUNA, N. D.; SUASSUNA, T. M. F. Desempenho de linhagens de amendoim sob alta severidade de doenças foliares. In: Anais do encontro sobre a cultura do amendoim, 14., 2017, Jaboticabal. Anais eletrônicos... Campinas, GALOÁ, 2017. Disponível em: $<$ https://proceedings.science/encontro-amendoim-2017/papers/desempenhode-linhagens-de-amendoim-sob-alta-severidade-de-doencas-foliares>. Acesso em: 26 jul. 2020.

SOUZA, A. P.; MOTA, L. L.; ZAMADEI, T. MARTIM, C. C.; ALMEIDA, F. T.; PAULINO, J. Classificação climática e balanço hídrico climatológico no estado de Mato Grosso. Nativa, v. 1, n. 1, p. 34-43, 2013.

UITDEWILLIGEN, G. S.; REICH, T. C.; CAPORUSSO, N. B.; SUASSUNA, N. D.; HEUERT, J.; SUASSUNA, T. M. F. Avaliação do desempenho de linhagens de amendoim em Jaboticabal, São Paulo, via modelos mistos. In: Anais do encontro sobre a cultura do amendoim, 14., 2017, Jaboticabal. Anais eletrônicos... Campinas, GALOÁ, 2017. Disponível em: $<$ https://proceedings.science/encontro-amendoim-2017/papers/avaliacao-dodesempenho-de-linhagens-de-amendoim-em-jaboticabal--sao-paulo--viamodelos-mistos>. Acesso em: 27 jul. 2020. 